\section{Tipo uma menina: estereótipo e formas de subjetivação}

Type one girl stereotype and forms of subjectivation

Patrícia Luiza Gonçalves TRINDADE (FURG) p_trindade@yahoo.com.br Marilei Resmini GRANTHAM (FURG) grantham@vetorial.net

\title{
00000000000
}

TRINDADE, Patrícia Luiza Gonçalves; GRANTHAM, Marilei Resmini. Tipo uma menina: estereótipo e formas de subjetivação. Entrepalavras, Fortaleza, v. 6, n. 2, p. 252-273, jul./ dez. 2016.

Resumo: Tendo como aporte teórico a Análise do Discurso de corrente francesa, pretendemos colocar em pauta, neste estudo, a noção de estereótipo, pelo viés da análise dos gestos de interpretação realizados no vídeo publicitário do absorvente Always: \#Tipo uma menina, da $P \& G$, endereçado a meninas. A ideia é revelar os efeitos de sentidos produzidos a partir do apelo feito a vários entrevistados, para "correr tipo uma menina", "brigar tipo uma menina" e "arremessar bola tipo uma menina". O trabalho se caracteriza por ser de cunho investigativo, com a organização de um dispositivo de análise. O corpus é constituído pelos prints das cenas que compõem o vídeo e nos leva a refletir acerca das relações de gênero que envolvem o masculino e o feminino, bem como acerca do gênero textual anúncio publicitário.

Palavras-chave: Análise do Discurso. Estereótipo. Estudos de gênero. 
Abstract: Considering the French Discourse Analysis approach as a theoretical reference, it is our aim to elicit, in this study, the stereotype concept under the gesture interpretation analysis perspective, performed in Always pads' advertising video from P\&G to girls: \#LikeAGirl. The main idea is to reveal the meaning effects caused by requesting the many interviewees to "run like a girl", "fight like a girl" and "throw like a girl". The study is characterized by having an investigative nature with an analysis device organization. The corpus consists of screenshots from the video scenes and it leads us to reflect about gender relations considering male and female, as well as reflecting about advertising as a text genre.

Keywords: Discourse Analysis. Stereotype. Genre studies.

\section{Introdução}

O trabalho tem como objeto de estudo as questões do sentido, pensando-as pelo viés da noção de estereótipo, o qual será tomado em uma perspectiva discursiva.

Com este objetivo, propomo-nos a examinar um vídeo da $\mathbf{P} \& \mathbf{G}$, produzido em uma campanha para venda da marca de absorventes Always, no qual se realiza uma interessante reflexão sobre o que seria fazer coisas "Tipo uma menina". O vídeo mostra uma audição para que várias pessoas - mulheres e homens adultos, meninos e meninas - foram convidadas a encenar situações que eram descritas assim: correr como uma menina, lutar como uma menina, arremessar uma bola como uma menina.

Segundo a marca de absorventes Always, o slogan \#LikeAGirl representa a força, o talento e o famoso girl power que toda menina tem. A campanha tem como objetivo principal estimular discussões, usando o conceito histórico de que meninas e mulheres são consideradas mais frágeis e delicadas e, com base neste pressuposto, a P\&G em junho de 2014 resolveu mostrar que meninas são fortes, sim, e que, mesmo em seus dias de menarca, podem continuar a realizar suas atividades.

A escolha desse objeto de estudo deu-se a partir do desejo de refletir sobre como os sentidos são construídos, desconstruídos e reconstruídos ao longo do tempo e através da publicidade. É sabido que essa forma de ação e interação social tem como propósito comunicativo a persuasão, a sedução, ou seja, levar o consumidor a comprar um produto, serviço ou ideia. Desta forma, pode-se dizer que o gênero publicitário busca persuadir e/ou seduzir a audiência não só para modificar o seu comportamento, como também para reforçá-lo. Assim, a publicidade, baseada nos valores socioculturais e históricos da sociedade, busca fazer com que o consumidor se identifique com os valores atribuídos ao 
v. 6 (2)

$252-273$

jul/dez

2016

produto veiculado.

A publicidade, assim, age sobre o outro, para levá-lo a fazer e/ ou a querer/fazer alguma coisa, muitas vezes intensificando valores que talvez o consumidor não os tenha, mas também reforçando aqueles valores que já os tem por meio de um processo de identificação.

A partir de tais pressupostos teóricos, o objetivo geral desse artigo é realizar um estudo sobre as questões dos sentidos produzidos pela repetição e por uma forma específica de reprodução dos sentidos, o estereótipo.

Ao escolher a teoria da Análise do Discurso de matriz francesa para a realização deste trabalho, propomo-nos a realizar uma análise que ultrapasse os limites do linguístico e que nos permita perceber os efeitos de sentidos produzidos pelo discurso publicitário.

Podemos dizer que este tipo de discurso é um poderoso mecanismo de dominação. O efeito produzido por uma publicidade torna-se algo natural e simples, presente na vida social e individual dos sujeitos, por meio de uma linguagem simbólica carregada de força e de poder.

Queremos, neste ponto, marcar nossa posição teórica e afirmar que consideramos a publicidade, para além de um gênero textual, como discurso. Citamos então Pêcheux (1969, p. 82), para quem o discurso é, antes de tudo, efeito de sentido entre os interlocutores, os quais representam lugares determinados na estrutura da formação social. O discurso materializa-se sob a forma de texto, que não é um objeto fechado em si mesmo, pois sempre tem relação com a situação e com outros textos.

Como o anúncio publicitário em exame trata, essencialmente, do que é agir "tipo uma menina", podemos dizer que este estudo aborda também questões de gênero, um campo de pesquisa acadêmica interdisciplinar que procura compreender as relações de gênero feminino, transgeneridade e masculino - - na cultura e sociedade humanas. As discussões teóricas sobre gênero podem ser divididas entre as relacionadas às características sexuais biológicas, supostamente fixas ou geneticamente determinadas na diferença entre homem e mulher, ou culturalmente determinadas, de onde se infere que a identidade de gênero masculino ou feminino é uma construção cultural, determinada por padrões de uma sociedade.

Nesta medida, a distinção entre gênero feminino e masculino trata-se de uma convenção social, cultural, histórica e discursiva, que se dá mediante relações de poder, produzindo mulheres e homens, 
distinguindo-os como corpos "femininos" e corpos "masculinos". Operar com o conceito de gênero ${ }^{1}$, portanto, significa operar numa abordagem que se coloca contra a naturalização do feminino e do masculino, na direção de compreender que, ao longo da vida, através das diversas instituições e práticas sociais, nos constituímos como mulheres e homens.

É intenção deste trabalho, também, colocar em foco questões ligadas à sala de aula, uma vez que aponta a possibilidade de trabalho com materiais que tratem de questões relativas ao gênero e incentivem a quebra dos preconceitos, já que isso tem sido uma preocupação constante por parte dos professores.

Finalmente, diríamos que a opção de trabalhar com a noção de estereótipo e com o discurso publicitário explica também a nossa opção pela Análise do Discurso, teoria que, por seu dispositivo teórico e analítico, vai nos permitir compreender a publicidade para além da sua função de venda.

\section{Análise do discurso, estereótipo, publicidade}

Este estudo filia-se à Análise do Discurso de linha francesa, teoria que surgiu na França na década de 60, tendo como seu precursor Michel Pêcheux, e tem sido difundida por Eni Orlandi, no Brasil. É considerada uma disciplina de entremeio, que se estrutura no espaço entre a Linguística e as Ciências de Formações Sociais. Ela foi pensada, de acordo com Pêcheux (1999, p. 14), como uma "disciplina de interpretação", capaz de construir procedimentos que expõem o olhar-leitor a níveis opacos e à ação estratégica de um sujeito. Para Eni Orlandi (2007, p. 16), os estudos discursivos visam a pensar o sentido dimensionado no tempo e no espaço das práticas do homem, descentrando a noção de sujeito e revitalizando a autonomia do objeto da Linguística.

A Análise do Discurso difere de uma análise que se prenda basicamente a questões históricas ou à estrutura dos textos, considerando, para tanto, outras noções postuladas por Michel Pêcheux, como os conceitos de "discurso", "formação imaginária", "formação discursiva", "interdiscurso" e "heterogeneidade enunciativa", entre

1 É importante salientar que este trabalho não tem a pretensão de enquadrar-se no que se tem chamado de campo intelectual de estudos de gênero, e, por isso, não se reporta a uma bibliografia mais específica. Queremos, antes, refletir sobre a forma como, discursivamente, a mulher vem sendo representada e sobre a maneira como ela tem se auto-representado. 
v. 6 (2)

$252-273$

jul/dez

2016

outros. Esses conceitos, que serão mobilizados na análise discursiva, levam em conta a relação existente entre ideologia e linguagem, a inscrição da língua na história e o papel fundamental do sujeito na significação dos elementos que compõem a língua enquanto sistema. A $\mathrm{AD}$, assim, toma o discurso como objeto de estudo e a linguagem como mediadora indispensável entre o homem e o meio social e natural em que vive.

Ao eleger o discurso como seu objeto, a AD procura compreender a língua fazendo sentido, como trabalho simbólico, parte do trabalho social geral, que é constitutivo do homem e da sua história. A linguagem, para a Análise do Discurso, é mediação entre a realidade natural e social. Pode-se dizer, nesta perspectiva, que a materialidade especifica da ideologia é o discurso e a materialidade do discurso é a língua.

Nesta perspectiva, podemos considerar o anúncio publicitário como um discurso que tem a finalidade de promover a marca de um produto, de uma empresa, de uma ideia. Sua linguagem geralmente se adapta ao perfil do público ao qual ele se destina e ao suporte ou veículo em que é publicado.

A fim de alcançar seu objetivo, o discurso publicitário se produz a partir daquilo que Pêcheux (1969, p.77) denomina de formações imaginárias, quando afirma que todo discurso deve ser remetido às relações de sentido nas quais é produzido, pois um discurso remete a outro discurso, frente ao qual é uma resposta direta ou indireta. Em outras palavras: o processo discursivo não tem início e o que funciona, na verdade, é uma série de formações imaginárias que designam o lugar que destinador e destinatário se atribuem cada um a si e ao outro, a imagem que eles fazem do seu próprio lugar e do lugar do outro.

O conceito de formação imaginária desenvolvido por Pêcheux pressupõe outras três categorias (antecipação, relações de força e relações de sentido), através das quais este conceito é capaz de se manifestar no processo discursivo. A primeira destas categorias, a antecipação, aponta para a presença de um enunciador que idealiza uma figura mental (representação imaginária) de seu interlocutor e, por meio desta figura mental, determina as condições de produção das quais poderá se utilizar e quais serão suas estratégias discursivas. As relações de força no discurso são determinadas pelos lugares sociais ocupados pelos sujeitos enunciadores: aquele que ocupa o lugar social de maior prestígio e poder que detêm, ao menos em teoria, maior força no processo discursivo. Já as relações de sentido estabelecem 
interdiscursividade com outros textos, uma vez que os discursos estão em contato constante uns com os outros.

Portanto, o conceito de formação imaginária não tem a ver com sujeitos empíricos, mas com representações mentais do que possivelmente aquele interlocutor simbolizaria no mundo real, ou seja, qual o lugar social ocupado por este sujeito, quais discursos ele conhece ou desconhece. Este conceito, aliado às condições de produção do discurso, é quem determina qual linguagem será utilizada, quais ideias estarão presentes, qual a intensidade e agressividade do discurso, já que todos estes fatores dependerão da imagem mental que o enunciador terá formado de seu interlocutor. A formação imaginária ocorre duplamente: o emissor faz uma imagem do receptor que, por sua vez, também tem determinada imagem de seu emissor.

Acreditamos que, no discurso publicitário e, portanto neste anúncio que é objeto de nosso estudo e análise, essa noção de formações imaginárias possa ser pensada como fortemente constitutiva. Na verdade, são as formações imaginárias que atuam fortemente na construção dos estereótipos de gênero.

Esta noção de estereótipo nos lembra que o sujeito é afetado por dois tipos de esquecimento, um que lhe dá a ilusão de ser a fonte do sentido (esquecimento $n^{0} 1$ ), e outro que lhe dá a ilusão de ser dono de seu próprio processo de enunciação (esquecimento $n^{0} 2$ ).

Pelo discurso do sujeito, assim, pode-se chegar à formação discursiva do sujeito, a qual, segundo Pêcheux (1988, p. 162), "dissimula, pela transparência do sentido que nela se constitui, sua dependência com respeito ao todo complexo com dominante das formações discursivas".

Esse "todo complexo com dominante" das formações discursivas é o que Pêcheux chama de interdiscurso, dizendo que ele é submetido à lei de desigualdade - contradição - subordinação que caracteriza o complexo das formações ideológicas.

O próprio de toda formação discursiva é dissimular a objetividade material contraditória do interdiscurso, apagando que "algo fala" sempre antes, em outro lugar e independentemente, ou seja, que há sempre um pré-construído, elemento constitutivo do interdiscurso que designa uma construção anterior, exterior e independente, por oposição ao que é construído na enunciação. Ele marca uma relação entre o interdiscurso, como lugar de construção do pré-construído, e o intradiscurso, como lugar da enunciação por um sujeito.

Desta forma, e segundo Pêcheux, o pré-construído é o "sempre- 
v. 6 (2)

$252-273$

jul/dez

2016

já-lá" da interpelação ideológica que fornece-impõe a realidade e seu sentido sob a forma da universalidade.

Na verdade, o estereótipo funciona como esse já-lá, como esse pré-construído.

O conceito de estereótipo foi criado em 1922, pelo escritor estadunidense Walter Lippmann e pode ser compreendido como uma imagem entreposta entre o indivíduo e a realidade, com caráter subjetivo e pessoal. Portanto, pode ser considerado uma generalização perigosa, falsa e reveladora de falta de conhecimento, podendo apenas ser modificada através de uma educação que conscientize a pessoa da ausência de fundamento dos seus juízos.

Segundo Barthes (1975), o estereótipo é uma necrose da linguagem, grave e deformada; no fundo, um oportunismo. O autor afirma que uma sociedade produz estereótipos, imagens fixas, cúmulos de artifício. Para ele, "é a palavra repetida, [...] é a via atual da 'verdade', o traço palpável que faz transitar o ornamento inventado para a forma canonical, coercitiva, do significado" (BARTHES, 1999, p.57-58).

Quando se trata de estereótipos que envolvem a mulher, estamos diante de esterótipos de gênero, nos quais a imagem feminina é frequentemente julgada a partir do conjunto de crenças que cercam principalmente a sua função de mãe e dona de casa, sua posição de sexo frágil, mostrada como objeto sexual, submissa ou serviçal.

Scott (1995, p. 89) nos diz, sobre o gênero, que é a construção social que uma dada cultura estabelece ou elege em relação a homens e mulheres, um elemento constitutivo das relações sociais fundadas sobre as diferenças percebidas entre os sexos, que fornece um meio de decodificar o significado e de compreender as complexas conexões entre várias formas de interação humana.

Na visão da autora, o gênero, ao enfatizar o caráter fundamentalmente social das divisões baseadas no sexo, possibilita perceber as representações e apresentações das diferenças sexuais. Imbricadas às diferenças biológicas existentes entre homens e mulheres, estão outras, social e culturalmente construídas. Dessa maneira, a ênfase dada pelo conceito de gênero à construção social das diferenças sexuais não se propõe a desprezar as diferenças biológicas existentes entre homens e mulheres, mas considera que, com base nestas, outras são construídas.

Nesse sentido, Bourdieu (1995, p.134) lembra que o mundo social constrói o corpo por meio de um trabalho permanente de formação 
e imprime nele um programa de percepção, de apreciação e de ação. Nesse processo, as diferenças socialmente construídas acabam sendo consideradas naturais inscritas no biológico e legitimadoras de uma relação de dominação.

Em relação ao gênero, há vários estereótipos, que podem ser definidos como as representações generalizadas e socialmente valorizadas acerca do que os homens e as mulheres devem ser e fazer. Por exemplo: rosa é cor de menina, homens não choram, TPM deixa as mulheres irracionais, etc.

O estereótipo de gênero é, pois, o conjunto de crenças acerca dos atributos pessoais adequados a homens e mulheres, sejam estas crenças individuais ou partilhadas.

São questões como essas que pretendemos abordar neste trabalho.

\section{O funcionamento discursivo do estereótipo}

Abordaremos aqui os princípios metodológicos e analíticos que norteiam nossa análise. Nossa análise constitui-se no exame de alguns gestos de interpretação realizados a partir de solicitações, aos entrevistados, sobre o que seria agir "tipo menina" em situações como: correr tipo uma menina, brigar tipo uma menina, arremessar uma bola tipo uma menina.

Em nosso processo analítico, partiremos dos enunciados que materializam as solicitações feitas aos entrevistados e que desencadearam todos os gestos de interpretação realizados. As encenações e respostas do vídeo evidenciam os dois grandes efeitos de sentido encontrados, aos quais denominamos de "delicadeza excessiva" e "atitude".

Com finalidades metodológicas, o vídeo será analisado através de imagens, de prints de sequências do vídeo.

A análise dos gestos de interpretação dos enunciados nos levaram a dois efeitos de sentido predominantes e que são representação de diferentes gestos de interpretação: a um denominamos de "delicadeza excessiva"; ao outro, de "atitude". 
v. 6 (2) 252-273 jul/dez 2016

1) Enunciado 1: correr tipo uma menina Efeito de sentido 1: delicadeza excessiva
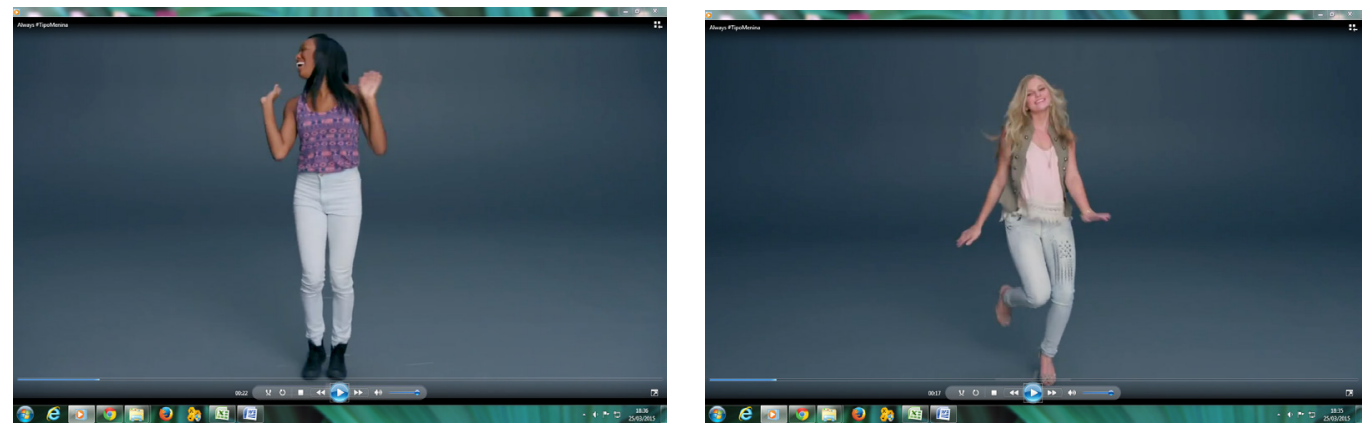

Tudo nessas imagens produz o efeito de sentido de uma delicadeza excessiva. e (re) produz o estereótipo que relaciona a mulher à imagem de fragilidade e de "frescura".

Estamos diante de um estereótipo de gênero. Gostar de esportes, correr, portanto, faz parte desse imaginário que relaciona a mulher à masculinidade. A tentativa de fugira esseimaginário acaba determinando, inconscientemente, essas entrevistadas que, tentando "correr tipo uma menina", carregam seus gestos de atitudes excessivamente delicadas.

Dessa forma, ocorre uma identificação com uma formação discursiva em que o que pode e deve ser dito é que mulheres devem ser femininas. Esse discurso, de forma inconsciente, reafirma um estereótipo sustentado socialmente por muito tempo e que relaciona a mulher ao desinteresse de praticar esportes.

Assim, esse discurso nos joga para a exterioridade, para o início do século XIX, quando as mulheres eram proibidas de praticar esportes porque "pertenciam ao lar".

A propósito, no período da $1^{\text {a }}$ Guerra Mundial as mulheres aprenderam a desempenhar papéis masculinos, o que as fez lutar de modo crescente por seus direitos. No entanto, apenas as mulheres com melhores condições financeiras tiveram a oportunidade de entrar nos clubes de tênis. Em 1920 foram organizados os primeiros campeonatos de atletismo feminino.

Foram abertas duas possibilidades para as mulheres que desejavam participar de esportes competitivos: fazer parte dos "esportes de homens" ou organizar suas próprias competições. Dessa maneira foram criados os Jogos Mundiais Femininos, ocorridos em 1921, 1922 e 1923. Graças ao êxito destes jogos foi muito mais fácil organizar outros encontros esportivos internacionais. 
Esse estereótipo da fragilidade e da fraqueza, como vimos, é reproduzido nesse discurso sobre "correr tipo uma menina". E reaparece no final do vídeo, quando a entrevistada é questionada da seguinte forma, como mostrado abaixo: como você acha que as afeta quando alguém usa "tipo uma menina" como um insulto?

A essa pergunta, a entrevistada responde:

- Com certeza afeta a autoconfiança delas. E nessa idade as meninas estão tentando entender elas mesmas e mostrar quem elas são, e quando alguém fala você faz coisas "tipo uma menina" é como se as diminuíssem. Porque elas acreditam que são fortes e dizer isso é a mesma coisa de dizer que elas são fracas e não tão boas quanto acreditam ser.

O que vemos, aqui, é o funcionamento discursivo do estereótipo, ou seja, a reprodução de um saber que é aceito por uma determinada sociedade e que é reproduzido de forma inconsciente e sem avaliação. É quase uma voz social que fala pelo sujeito, sem que ele deixe falar sua própria voz. Neste vídeo, é somente no momento em que a entrevistada é convidada a refletir sobre sua encenação, que esta permite que sua própria voz venha a falar e a produzir um sentido diferente daquele criado pelo estereótipo. É isso que leva a entrevistada a reconhecer que "tipo uma menina" afeta a autoconfiança, diminui, torna a pessoa fraca.

Efeito de sentido 2: atitude
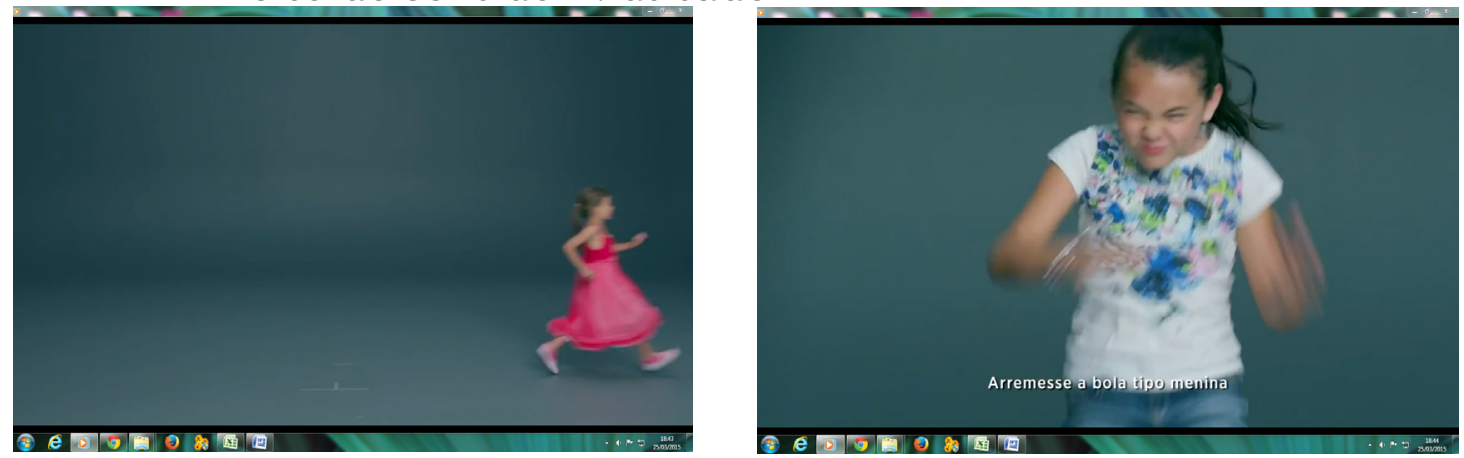

Fonte: https://youtu.be/mOdALoB7Q-0

O exame das imagens mostra que, diante da solicitação para correr "tipo uma menina", as entrevistadas agem de forma diferente daquelas verificadas anteriormente. Vemos uma menina de aproximadamente sete anos de idade, com um vestido cor de rosa, que, ao ser solicitada a "correr tipo uma menina", corre pelo estúdio o mais rápido que pode. E uma outra menina que corre sem sair do lugar, que movimenta os braços na altura da cintura, de maneira rápida; sua expressão facial 
v. 6 (2)

$252-273$

$\mathrm{jul} / \mathrm{dez}$

2016

demonstra a força que está empregando para dar velocidade à corrida.

A análise nos chama atenção, inicialmente, para o vestido rosa da menina. E isso nos leva novamente à questão do estereótipo e nos remete para a exterioridade desse discurso. Ali descobrimos que, na verdade, a cor rosa, associada às meninas, não tem a ver com biologia ou psicologia, e sim com marketing. Até o fim do século XIX, tintura de tecido era cara, então os pais não se preocupavam com isso. A definição das cores "certas" para cada gênero surgiu só no início do século XX. E era o inverso da atual. Um catálogo de roupas dos EUA de 1918 dizia que o rosa, por ser mais forte, era adequado aos garotos. E o azul, por ser delicado, às garotas. Foi só entre 1920 e 1950 que as lojas começaram a sugerir azul para eles e rosa para elas, como forma de agitar as vendas. Essa imposição social tem sido reforçada desde então.

Esse gesto de interpretação, portanto, produz um jogo entre dois estados de mundo: um que reproduz o estereótipo da feminilidade ligada a um vestido rodado e rosa; outro que produz o sentido de que meninas são ágeis, rápidas e hábeis na prática de esportes.

É interessante notar, no entanto, que a ideia da existência de "jogos de meninas" ainda é comum, mesmo nos dias de hoje. Entre estes, aparecem: dança, ginástica, patinação, patinação no gelo, vôlei. A própria publicidade, inclusive, ainda trabalha com a ideia de separação de gênero, como, por exemplo, a oferta de um jogo para meninas, oferecido da seguinte forma:

Descrição do Jogo: É fato que o preconceito está em todos os lugares, inclusive no esporte onde muitos definem os esportes para meninas e esportes para meninos, mas é claro que isso não pode e não deve acontecer, por isso que estamos trazendo este jogo de luta de boxe especialmente para meninas que adoram praticar esportes, principalmente esportes ligados à luta. Prove que as meninas também podem praticar esportes mais violentos como o boxe, $M M A$ e outros esportes. Coloque as luvas de boxe e entre no ringue com toda força para derrotar as outras meninas durante o jogo, mostre habilidade, concentração e raciocínio rápido para atacar e se defender sempre que necessário, assim conseguirá vencer facilmente todas as adversárias. Teremos várias lutas acontecendo a todo o instante, então tome cuidado sempre que passar de fase, pois as adversárias estarão mais preparadas e serão mais fortes, consequentemente o jogo ficará muito mais difícil. o jogo é uma ótima oportunidade para você que quer treinar e lutar boxe poder aprender os princípios básicos do esporte, além de poder se divertir é claro. Se você já brincou neste e em outros jogos de esportes para meninas poderá aproveitar outros jogos interessantes que temos no site, inclusive os jogos de esportes para meninos ${ }^{2}$

2 http://jogosonlinegratis.uol.com.br/jogoonline/esporte-para-meninas/ 
Nesta descrição do jogo para meninas, observamos, mais uma vez, o funcionamento discursivo do estereótipo, numa espécie de jogo entre o sentido estabelecido (o de que existem esportes para meninas e esportes para meninos) e um novo sentido que tenta se estabelecer (isso não pode e não deve acontecer, é preconceito). O que o discurso revela é o sujeito tentando escapar do sentido estabelecido, ou seja, do estereótipo. No entanto, o sentido cristalizado retorna de forma bem evidente e é revelado através das marcas linguísticas da restritiva (meninas que adoram praticar esportes) ou do sentido produzido pelo emprego de verbos no imperativo em construções como: prove que as meninas também podem praticar esportes mais violentos; mostre habilidade, concentração e raciocínio rápido. Quer dizer: se é preciso provar, é porque existe um saber contrário, é porque ainda existe a dúvida - embora a publicidade esteja oferecendo um jogo "de meninos" para as meninas - de que elas sejam capazes de executar esportes mais violentos, ter habilidade, concentração e raciocínio.

O efeito de sentido de que as meninas são capazes de ter energia e determinação é reforçado quando a entrevistadora faz uma outra pergunta à menina de vestido rosa, após a encenação em que ela sai correndo rápido pelo estúdio, reproduzindo rapidez e agilidade: o que significa para você quando eu digo "corra tipo uma menina"?

A esta pergunta, a menina responde:

- Pra mim significa: "corra o mais rápido que você puder".

Essa resposta nos mostra um discurso que revela novas condições de produção. É uma nova forma de relação com o estereótipo da fragilidade feminina, no que tange à prática de esportes.

Um efeito de sentido semelhante pode ser observado quando a entrevistadora, no final do vídeo, faz outra pergunta, desta vez para a moça que, antes, correra com delicadeza: "Se eu te pedisse para "correr tipo uma menina" agora, você faria algo diferente?

A resposta dada foi:

\section{- Sim, eu correria do meu jeito.}

Observe-se a imagem. 
v. 6 (2)

252-273 jul/dez 2016

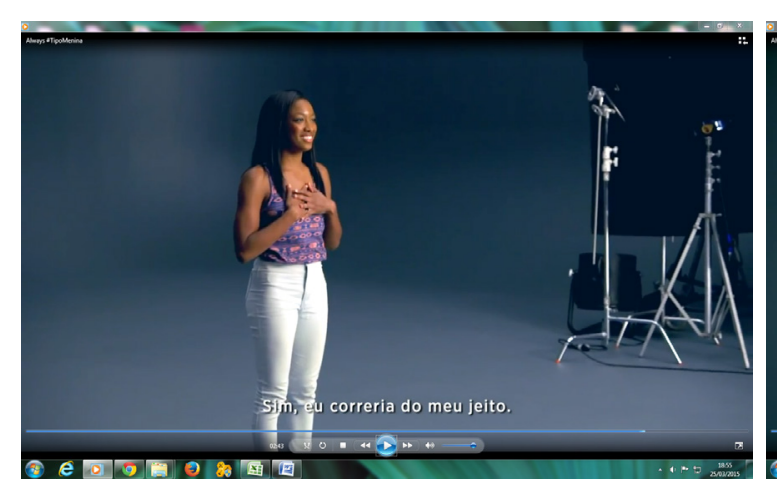

Fonte: https://youtu.be/mOdALoB7Q-0

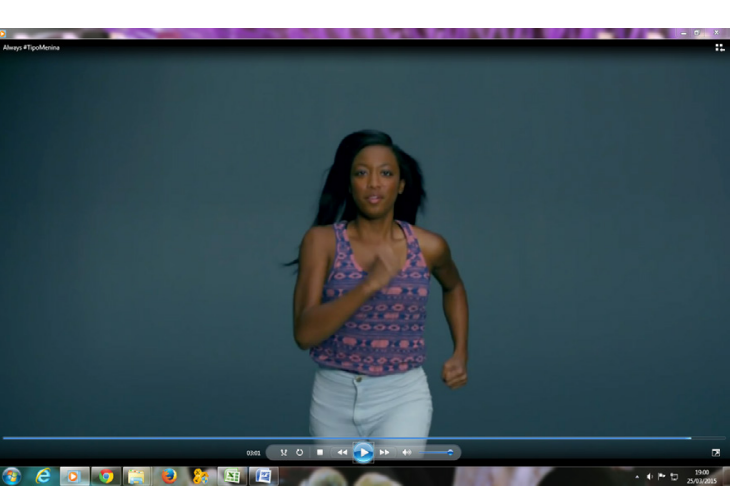

Mais uma vez percebemos o funcionamento discursivo do estereótipo, que produz um jogo entre um sentido dominante e cristalizado e um sentido que vem sendo construído.

Isso fica claro ao observarmos a imagem de uma nova forma de correr e a expressão do meu jeito. Na verdade, essa expressão traz para esse discurso o discurso-outro, o de que mulheres são delicadas e frágeis e devem manter essa postura inclusive quando praticam esportes, quando correm.

Percebemos então, que essa moça, nessas imagens, não se submete ao estereótipo, ao discurso-outro, e mostra sua identificação com uma formação discursiva em que o que pode e deve ser dito é que mulheres correm, simplesmente.

2) Enunciado 2: brigar tipo uma menina

Efeito de sentido 1: delicadeza excessiva
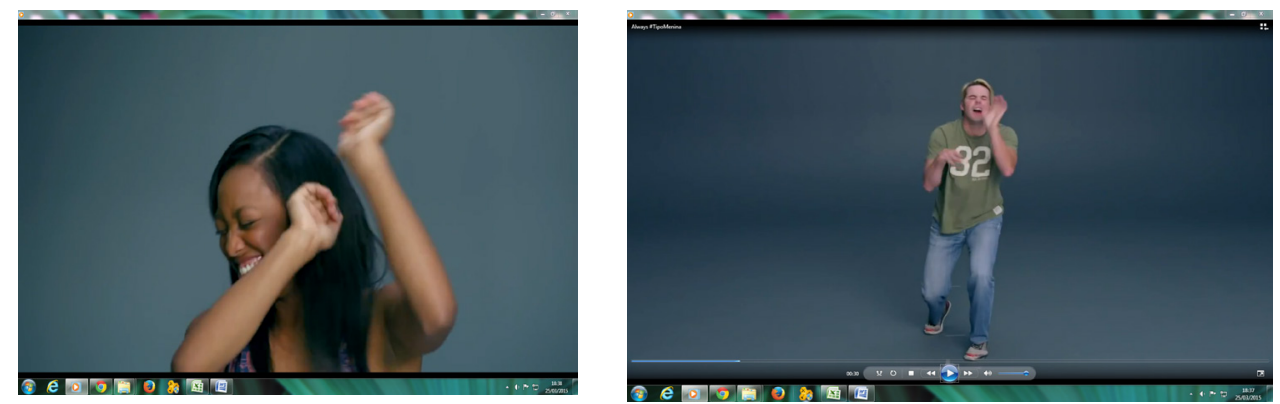

Fonte: https://youtu.be/mOdALoB7Q-0

O exame das imagens nos mostra que, diante da solicitação para "brigar tipo uma menina", a moça coloca os braços na altura de seu rosto, fica com as mãos entreabertas, vira o rosto para o lado e sorri; já o rapaz atende à solicitação ficando com as pernas afastadas, com os braços à frente de seu corpo, e com as mãos ele faz um gesto como se estivesse abanando alguém, e ainda faz um som estranho com a boca aberta. 
É a naturalização da imagem da mulher como fraca ou fisicamente incapaz de brigar de forma eficiente, com vigor, com vontade, com força, que vemos nessas imagens. Temos então um reforço do estereótipo da fragilidade e da incompetência feminina. E a identificação dos sujeitos com a formação discursiva dominante, aquela em que o que pode e deve ser dito é que as mulheres devem ser criaturas dóceis e delicadas.

Efeito de sentido 2: atitude
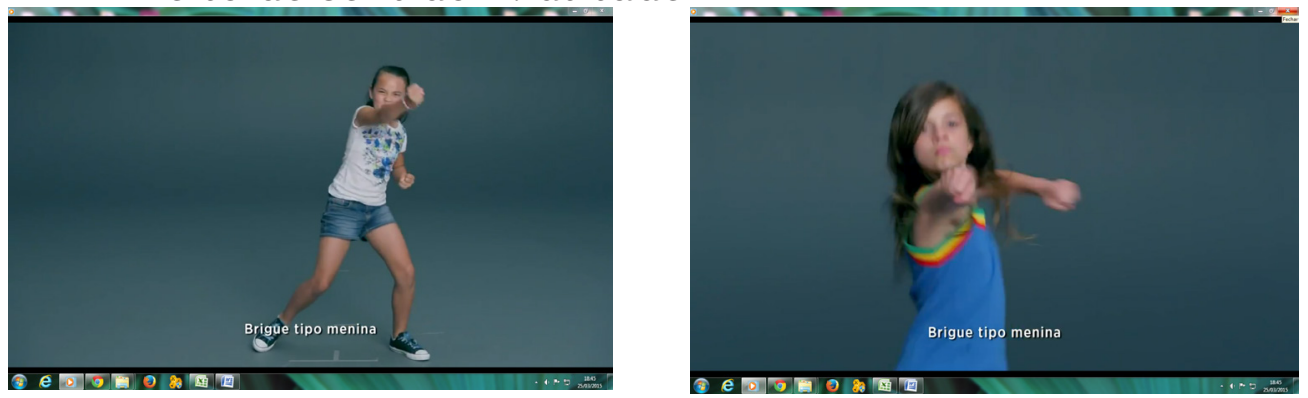

Fonte: https://youtu.be/mOdALoB7Q-o

Vemos aqui uma menina que, ao ser solicitada a brigar "tipo uma menina", afasta suas pernas e, com o punho fechado, executa a ação como estivesse dando um soco muito forte; ela mostra uma expressão de quem está muito brava e concentrada, demonstrando energia no que está fazendo. Vemos também outra menina que, como a anterior, tem uma expressão facial fechada e concentrada e que também disfere um soco, demonstrando muita força e energia.

Tal observação nos conduz a um dos princípios fundantes da $\mathrm{AD}$, o de condições de produção do discurso, e nos mostra que não é o sujeito que se apropria da linguagem, num movimento individual, mas que há uma forma social de apropriação da linguagem em que se reflete a ilusão do sujeito, ou seja, sua interpelação pela ideologia. E é nesse jogo, do lugar social e dos sentidos estabelecidos, que se representa a determinação histórico-social do discurso.

Desta forma, a maneira como as meninas mais jovens interpretaram as ações revela o seu discurso, que é produzido em um contexto sócio histórico cultural no qual a imagem feminina vem sofrendo grandes transformações.

O que temos aqui, portanto, é uma outra forma de identificação com a formação discursiva dominante, e uma outra forma de relação com o estereótipo. Tais encenações mexem com a rede de significações construída sobre a relação da mulher com esportes considerados violentos ou masculinos. 
v. 6 (2)

252-273

jul/dez

2016
3) Enunciado 3: arremessar uma bola tipo uma menina Efeito de sentido 1: a delicadeza

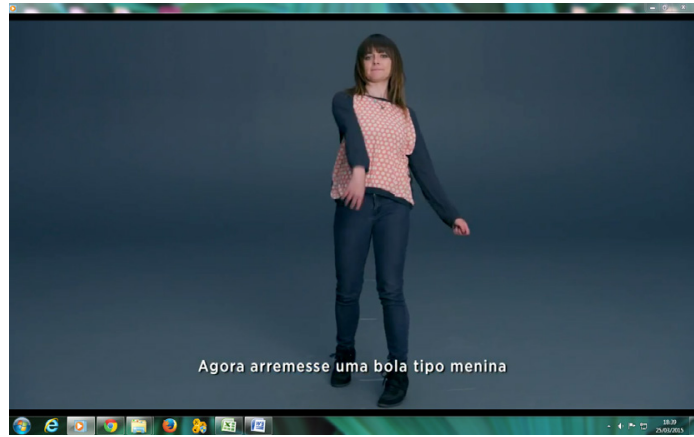

Fonte: https://youtu.be/mOdALoB7Q-0

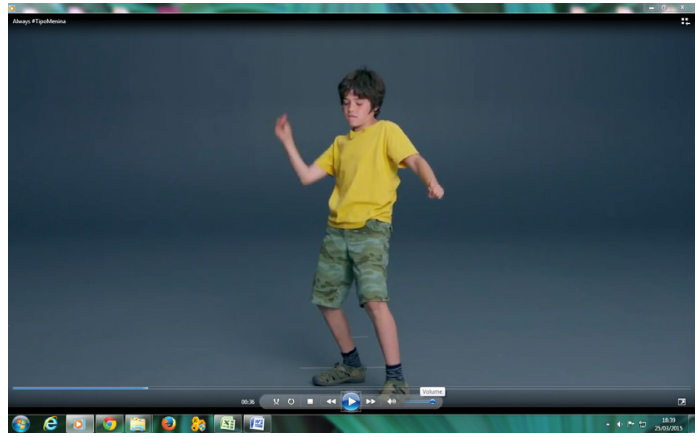

A análise das imagens nos mostra uma jovem mulher que, ao ser solicitada a arremessar uma bola "tipo uma menina", arremassa de maneira delicada, como se não estivesse com vontade de executar a ação. De forma semelhante, temos um menino que executa a ação de maneira extremamente delicada, tanto que, antes mesmo de arremessar, deixa a bola cair no chão, emitindo um som de lamentação: "aaaahhh" .

Assim como vimos ocorrer anteriormente, tais encenações representam a mulher como dotada de uma delicadeza excessiva, nos levando mais uma vez à questão do estereótipo, ou seja, a uma visão das mulheres como o sexo frágil, delicadas e sem força ativa para desempenhar a ação proposta de arremessar uma bola com vigor e eficiência.

Tal constatação nos remete a Mello (2002), quando o autor afirma que a sociedade sexista transmite às crianças a informação de que meninas e meninos são opostos. Tal comportamento é facilmente percebido no que se refere aos brinquedos, às brincadeiras e aos esportes e as instituições familiares e educacionais que dificultam um desenvolvimento corporal amplo, poupando as meninas de algumas atividades físicas e muitas vezes barrando o seu desenvolvimento no esporte.

Esse sentido de preconceito é o que vemos nesse discurso produzido pelo menino. Este é depois questionado, conforme mostramos a seguir: você acha que acabou de insultar sua irmã? O menino responde então à pergunta da seguinte forma: Não. Bom... na verdade eu insultei as meninas em geral, mas não a minha irmã. 


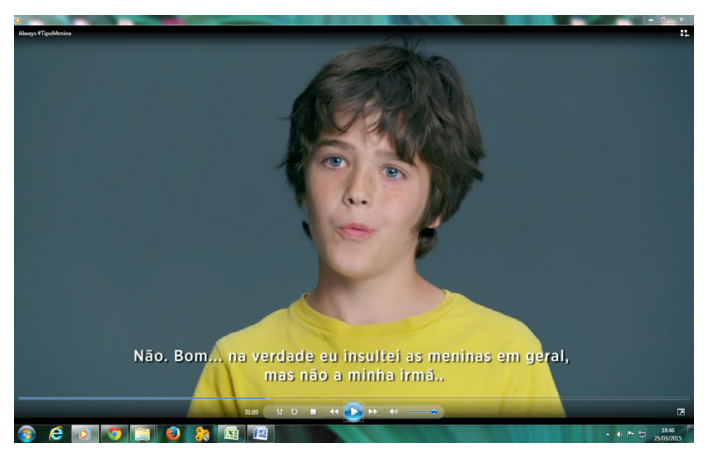

Fonte: https://youtu.be/mOdALoB7Q-0

Constatamos, nessa resposta, um enunciado dividido, em que aparecem duas posições dominadas por FD antagônicas (X e Y). Isso é o que Courtine (COURTINE, 2009, p.50) denomina enunciado dividido, o qual indica limites entre o formulável (FDX) e o não-formulável (FDY). Na FDX, o que pode ser dito é que houve insulto (eu insultei as meninas em geral); na FDY, o que pode ser dito é que não houve insulto (não a minha irmã).

Desse modo, o enunciado "eu insultei as meninas em geral, mas não a minha irmã" é uma representação contraditória, que estabelece uma divisão entre dois sujeitos de saber antagônicos.

Tal divisão representa a noção de posição-sujeito, que é, segundo Courtine, a relação de identificação do sujeito enunciador com o sujeito universal da FD.

Embora esse discurso seja produzido em tempos atuais, nos quais as mulheres destacam-se em todas as áreas da sociedade, inclusive nos esportes, ou seja, sob condições de produção distintas das que dominaram em outras épocas e em outras sociedades, este sujeito assume ainda uma posição-sujeito que reflete uma imagem cristalizada no imaginário masculino e que coloca as mulheres numa posição de incompetência e inferioridade.

Em outras palavras: esse discurso reproduz o estereótipo sobre a fragilidade e a incompetência feminina na prática de esportes. 
v. 6 (2)

252-273

$\mathrm{jul} / \mathrm{dez}$

2016
Efeito de sentido 2: a atitude
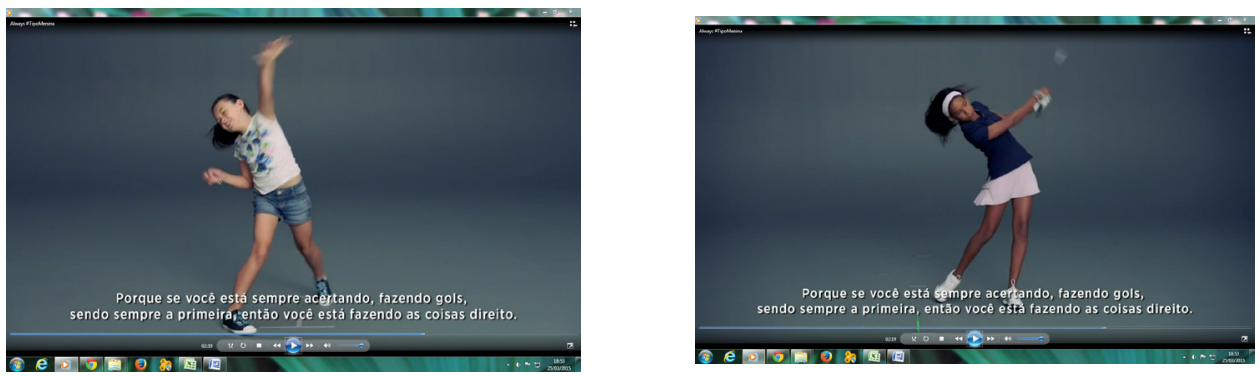

Fonte: https://youtu.be/mOdALoB7Q-0

O exame dessas imagens nos mostra que, diante da solicitação para arremessar uma bola "tipo uma menina", as entrevistadas assumem atitudes como: afastar as pernas e ganhar impulso, para que a bola vá o mais longe possível; utilizar um taco de golfe, e, com postura de jogadora, arremessar de maneira ágil e energica.

Desta forma, tudo nessas cenas produz um efeito de sentido de atitude, energia e força. Isso nos mostra as novas condições de produção desse discurso e o funcionamento do estereótipo, já que atualmente as mulheres têm mais exemplo de mulheres no esporte e em outras áreas, desempenhando seu papel muito bem. No entanto, em toda história do esporte, a mulher foi subjugada no que tange à conquista de seus direitos fundamentais de participação. A participação feminina cresceu ao mesmo tempo em que se acentuaram os processos de globalização do esporte e da institucionalização dos interesses das mulheres em participar de esportes, tanto aquáticos como terrestres. Atualmente, o modelo de mulher frágil já parece coisa do passado, principalmente no cenário esportivo, e a tendência feminina no esporte é a de ultrapassar os limites físicos e emocionais, colocando-se em pé de igualdade com os atletas masculinos.

Temos então, aqui, a imagem de uma mulher mais "ativa", diferente da imagem de "mulher frágil". Educadas num período em que se exige igualdade de direitos e que sexo frágil é coisa do passado, ou seja, sob diferentes condições sociais, as meninas entrevistadas neste vídeo revelam, em seu discurso, que não foram criadas obrigatoriamente para serem donas de casa e procriar, como acreditava a sociedade brasileira no início do século XX, mas que podem brincar como os meninos, realizar atividades que exigem força física, como arremessar bola, e serem bastante competitivas.

Esse efeito de sentido, o da capacidade e da atitude, que vai na direção contrária ao da delicadeza excessiva e da incompetência, ou 
seja, do estereótipo do "tipo uma menina" pode ser verificado ainda na cena analisada no final do vídeo, quando a menina é questionada como mostramos a seguir:
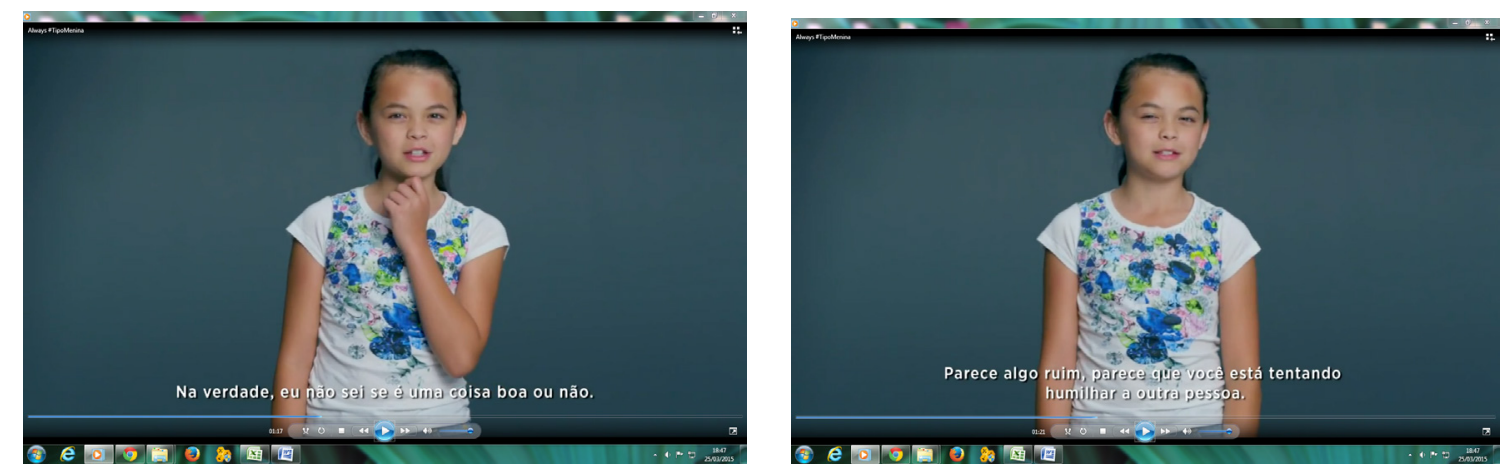

Fonte: https://youtu.be/mOdALoB7Q-0

"Tipo menina" é uma coisa boa?

- Na verdade, eu não sei se é uma coisa boa ou não. Parece algo ruim, parece que você está tentando humilhar outra pessoa.

O que vemos nesse discurso é um sujeito interpelado ideologicamente e afetado por um saber que é socialmente construído pelo estereótipo. Assim, esse sujeito mostra-se vacilante diante da formulação "tipo uma menina", sem saber se isso é uma coisa boa ou não, se é ruim ou não, se é humilhante ou não. No entanto, ao usar a expressão "parece algo ruim", "parece que você está tentando humilhar outra pessoa", ela revela a força desse estereótipo e dos sentidos por ele produzidos. O que se percebe é que as meninas mais jovens entrevistadas não entendem bem a formulação como um insulto e não se sentem coagidas a interpretar um ser inferior.

Temos aqui um sujeito dividido entre o sentido negativo do estereótipo e outros sentidos, produzidos sob condições sociais e históricas.

Essa divisão entre o estereótipo e um outro sentido é totalmente rechaçada no final do vídeo, como podemos constatar nas sequências em que aparece a pergunta "Qual o conselho que você daria a essas meninas quando alguém disser a elas que elas correm tipo menina, chutam tipo menina, batem tipo menina e nadam tipo menina?". Ao que a jovem responde: 
v. 6 (2)

252-273 jul/dez 2016

Fonte: https://youtu.be/mOdALoB7Q-0

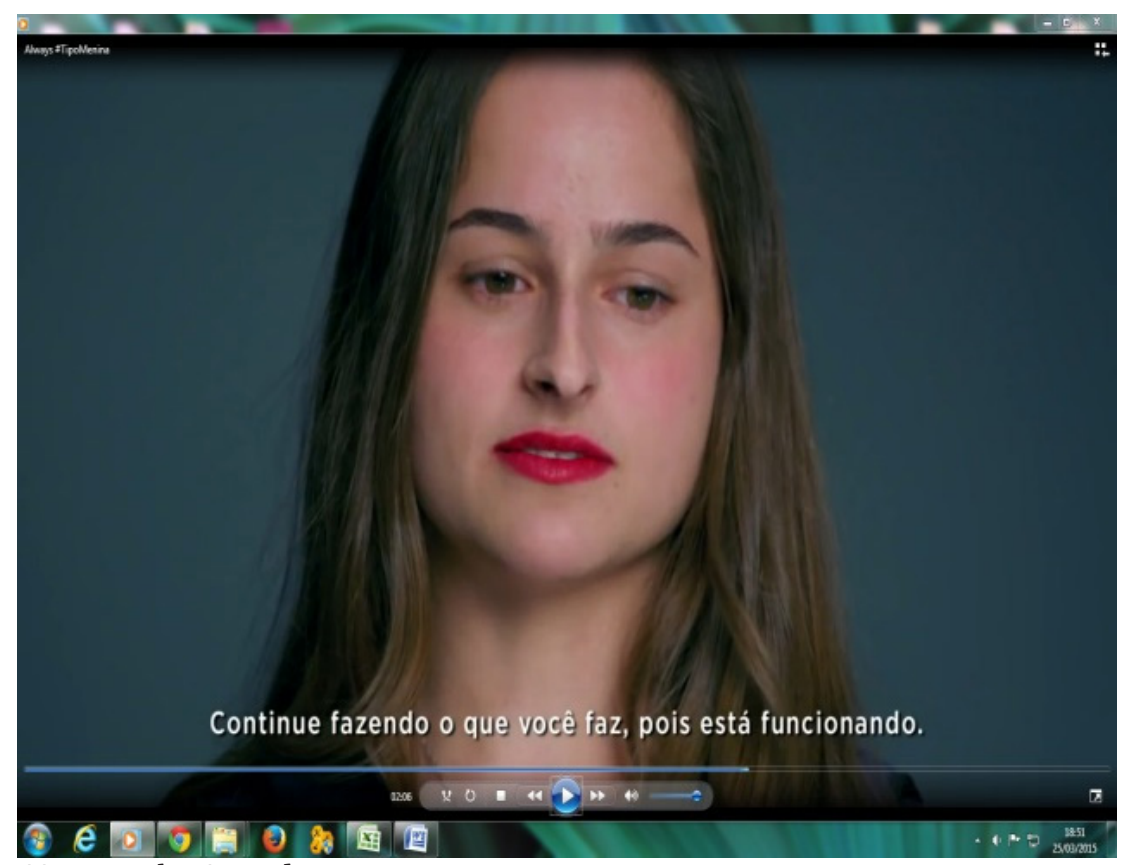

- Continue fazendo o que você faz, pois está funcionando. E se alguém disser que corre tipo menina, chuta tipo menina, pula tipo menina são coisas que você não deveria estar fazendo... Bom problema deles. Porque você está sempre acertando, fazendo gols, sendo sempre a primeira, então você esta fazendo as coisas direito. Não importe o que eles dizem, não se importe. Sim, eu corro tipo menina, eu chuto tipo menina, eu ando tipo menina e eu acordo tipo menina de manhã, porque eu sou uma menina e eu não tenho vergonha nenhuma disso, vou continuar fazendo tudo tipo menina. Esse é meu conselho.

Enquanto a entrevistada responde a pergunta, cenas de mulheres executando as ações propostas anteriormente são passadas, só que desta vez o resultado é completamente diferente do inicial, não mais caricatos e estereotipados. Esta nova atitude se deu depois de assistirem às meninas mais jovens executarem as ações e ao serem incentivadas pela diretora do vídeo a refletirem sobre a atuação que fizeram.

Aqui temos a completa rejeição ao estereótipo, como podemos perceber nas marcas problema deles, Não importe o que eles dizem, não se importe. Aqui, "tipo menina" é definitivamente considerado como algo positivo; Porque você está sempre acertando, fazendo gols, sendo sempre a primeira, então você esta fazendo as coisas direito; eu sou uma menina e eu não tenho vergonha nenhuma disso, vou continuar fazendo tudo tipo menina. 


\section{Considerações finais}

A análise realizada nos permite constatar, nesse processo discursivo, um mecanismo de antecipação, em que o destinador antevê as representações de seu destinatário e antecipa o imaginário do outro. Ou seja: há, nesses recortes, a idealização de uma figura mental, uma representação imaginária sobre o que, para os entrevistados, a figura feminina representa no mundo real. E é essa formação imaginária que leva os entrevistados a reproduzirem o estereótipo da menina ou mulher como o sexo frágil.

Assim, podemos dizer que esses sujeitos, a partir das formações imaginárias, reproduzem um discurso dominante na sociedade, o qual produz um saber que concebe as mulheres como frágeis e delicadas. Mesmo com as mudanças que ocorreram na sociedade entre o final do século XIX e o início do século XX, essa visão sobre as mulheres às vezes ainda continua a mesma, e as virtudes que dela se espera são doçura, passividade e submissão. A divisão entre masculino e feminino, assim, por certo está cristalizada e incorporada nas relações humanas, funcionando como um esquema cognitivo que é fortalecido pela experiência e pelas ações repetidas.

Esta é a representação feminina que constitui o imaginário dos entevistados desses recortes. E que cria, entre diversas interpretações sobre o que é "correr tipo uma menina", "brigar tipo uma menina" e "arremessar tipo uma menina", uma relação de paráfrase, com formulações que produzem o mesmo efeito de sentido.

Mas vemos também sujeitos identificando-se com outros saberes, contra-identificando-se com a ideologia e a FD dominante. O dizer desses sujeitos identifica-se, pois, com outra formação discursiva: uma FD em que o que pode e deve ser dito é que as mulheres são competentes, capazes, competidoras, atletas.

O que verificamos, portanto, em todo esse estudo, é o funcionamento discursivo do estereótipo, que produz, nos sujeitos, diferentes relações de identificação:

- o sujeito identifica-se plenamente com o estereótipo

- o sujeito apresenta-se dividido entre a manutenção do estereótipo e o rompimento com o mesmo

- o sujeito desidentifica-se com o estereótipo 
v. 6 (2)

252-273

$\mathrm{jul} / \mathrm{dez}$

2016

Percebemos, através do exame do vídeo, que a normalização da dicotomia "homens versus mulheres" acabou fundando uma forma de pensamento na qual há um jeito de ser feminino e outro de ser masculino. Desse modo, há comportamentos, falas, gestos, posturas físicas, além de atividades e funções, que são entendidas como adequadas para cada um. Essas características físicas e comportamentais são transmitidas para as crianças pela forma como são criadas e educadas, e o que é esperado para meninas e meninos é reforçado, de forma inconsciente, nos pequenos gestos e práticas do dia a dia. O mais comum, como pudemos constatar, é o aprisionamento da mulher em estereótipos que tentam "encaixá-la" em padrões considerados normais: delicada, frágil, "fresca", incompetente. Tais características delineiam a inferiorização da mulher, atestando uma ilusória dependência e passividade quando comparada à racionalidade do homem, à liberdade de ação eà participação social.

É assim que o estereótipo funciona discursivamente: produz um saber, um já-lá que retorna nos discursos, que são repetidos indefinidamente e aceitos sem contestação, o que produz um efeito de verdade.

\section{Referências}

BARTHES, R. Escritores, intelectuais, professores e outros ensaios, 1975.

BARTHES, R. O prazer do texto. São Paulo: Perspectiva, 1999.

BOURDIEU, Pierre. "A dominação masculina". Educação e Realidade, v.20, no 2. Porto Alegre, jul./dez. 1995, pp. 133-184.

Papel da memória. In: ACHARD, Pierre et al. (Org.). Papel da memória. Campinas: Pontes, 1999.

Semântica e Discurso: uma crítica à afirmação do óbvio. Campinas: Ed. Unicamp, 1988.

COURTINE, Jean-Jacques. Análise do discurso político: o discurso comunista endereçado aos cristãos. São Carlos: EdUFSCar, 2009.

JOGOS Online Grátis. Esporte para meninas. Disponível em: <http:// jogosonlinegratis.uol.com.br/jogoonline/esporte-para-meninas/>. Acesso em: 10 out. 2014 .

MELLO, L. M. Meninos e meninas como reféns de uma sociedade sexista. Revista Motricidade, Santa Maria da Feira Portugal, n. 2, 2002. Disponível em: $\quad<$ http://www.castelobranco.br/prppg/revista/Textos/artigo/sexista. htm>. Acesso em: 13 de agosto. de 2015. 
ORLANDI, Eni Puccinelli. Análise de Discurso: Princípios \& Procedimentos. 7.ed. Campinas, SP: Pontes, 2007.

PÊCHEUX, M. (1969). Analyse Authomatique du Discours, Dunod, Paris.

SCOTT, Joan. "Gênero: Uma categoria útil de análise histórica". Educação e Realidade, V. 20, no 2. Porto Alegre, jul./dez. 1995, pp. 79.

YUOTUBE, Site de vídeos. Disponível em: <https://youtu.be/mOdALoB7Q-0> Acesso em: 10 de outubro de 2014.

Recebido em: 31 de ago. de 2016.

Aceito em: 27 de dez. de 2016. 